\title{
Comparison of a bio-based corrosion inhibitor versus benzotriazole on corroded copper surfaces
}

\author{
Monica Albini $^{\mathrm{a}}$, , Paola Letardi ${ }^{\mathrm{c}}$, Lidia Mathys ${ }^{\mathrm{a}, \mathrm{b}}$, Laura Brambilla ${ }^{\mathrm{d}}$, Julie Schröter ${ }^{\mathrm{d}}$, Pilar Junier ${ }^{\mathrm{b}}$, \\ Edith Joseph ${ }^{\mathrm{a}, \mathrm{d}, *}$
}

${ }^{a}$ University of Neuchâtel, Institute of Chemistry, Laboratory of Technologies for Heritage Materials, Av. Bellevaux 51, 2000 Neuchatel, Switzerland

${ }^{\mathrm{b}}$ University of Neuchâtel, Institute of Biology, Laboratory of Microbiology, Emile-Argand 11, 2000 Neuchatel, Switzerland

${ }^{\mathrm{c}}$ National Research Council, Institute of Marine Sciences CNR-ISMAR, Via de Marini 6, 16149, Genoa, Italy

${ }^{\mathrm{d}}$ Haute Ecole Arc Conservation-Restauration, HES-SO, Espace de l'Europe 11, 2000 Neuchâtel, Switzerland

\section{A R T I C L E I N F O}

\section{Keywords:}

Copper (A)

SEM (B)

EIS (B)

IR spectroscopy (B)

Neutral inhibition $(C)$

Passive film (C)

\begin{abstract}
A B S T R A C T
This research aims to characterize and compare the protective behaviour of a bio-based treatment versus benzotriazole (BTA) for the preservation of copper-based artefacts affected by active corrosion induced by copper chlorides. For this, the treatments were applied on artificial copper hydroxychlorides produced on copper sample. Their inhibition performance was then investigated by Scanning Electron Microscopy, Infrared Spectroscopy and Electrochemical Impedance Spectroscopy. Results showed few BTA-Cu complexes formed and poor protectiveness of the BTA treatments. In contrast, the bio-based treatment resulted in the conversion of almost all copper hydroxychlorides into copper oxalates, providing a more efficient corrosion inhibition.
\end{abstract}

\section{Introduction}

Artefacts made of copper and its alloys undergo progressive and inevitable corrosion processes. Therefore, the identification of the degradation mechanisms and of the corrosion products involved thus is important to select the more adequate conservation-restoration approach [1]. One of the most harmful degradation phenomena observed on copper substrates is the so called "bronze disease" [2]. This corrosion process is caused by the interaction between copper and chloride ions in presence of oxygen and at high relative humidity producing nantokite (CuCl) [2]. The formation of nantokite in the presence of air and moisture causes a cyclic corrosion process that produces a green powdery layer of copper hydroxychlorides $\mathrm{Cu}_{2}(\mathrm{OH})_{3} \mathrm{Cl}$ on the artworks [3-5]. This corrosion product has three main polymorphic crystal forms: atacamite, clinoatacamite and botallackite [6]. Although copper hydroxychlorides are generally stable, in some cases, chloride ions can be released from $\mathrm{Cu}_{2}(\mathrm{OH})_{3} \mathrm{Cl}$ and lead to further corrosion of the artefact [2]. This cyclic reaction is the main cause of stress cracking, material loss and eventually the complete loss of the object.

In metal conservation, the use of corrosion inhibitors to decrease the corrosion rate of copper-based relics is a common practice [2]. The most largely used product for copper-based objects is benzotriazole (BTA) that has, for a long time, been considered as the reference corrosion inhibitor, particularly for archaeological objects. Initially adopted as a corrosion inhibitor for bare copper [7], BTA has been widely used in metal conservation since the description of its inhibition mechanism in 1963 [8]. Despite the extensive scientific literature published on the subject, conflicting evidence and opinions exist about its effectiveness [9-16]. It has been suggested that BTA efficiency is lower on corroded copper alloys than on bare copper [17]. Also, there are some concerns about its effectiveness on bronze disease since the layer of cupric chloride-BTA complexes formed after treatment would only be superficial and subject to eventual disruption, with reactivation of the corrosion processes underneath it [18]. However, the most controversial argument about the extensive use of BTA is its toxicity. As reported by Cano and Lafuente [17], some authors refer to BTA as an environmental and health hazard product, recommending to handle it with care $[2,13]$, while others describe it as only slightly toxic $[7,19]$. Thus, in the last decades the interest about alternative, sustainable and harmless products has increased [20].

The bio-based treatment employed here relies on the use of a naturally occurring fungal strain mixed in a hydrogel amended with nutrients. In fact, some fungal species are known for their ability to produce oxalic acid in order to immobilize heavy metals and, for example, detoxify polluted environment [21-23]. Oxalic acid can complex metal ions forming highly insoluble biogenic metal oxalates

\footnotetext{
* Corresponding author at: University of Neuchâtel, Institute of Chemistry, Laboratory of Technologies for Heritage Materials, Av. Bellevaux 51, and University of Applied Sciences HES-SO, Haute Ecole Arc Conservation-restauration, Espace de l'Europe 11, 2000 Neuchatel, Switzerland.

E-mail addresses: edith.joseph@unine.ch, edith.joseph@he-arc.ch (E. Joseph).
} 
[24,25]. This capability has already been exploited in the field of waste treatment [26-28]. Biogenic oxalic acid production could also be used to turn existing reactive copper corrosion products into more stable and less soluble compounds, while preserving the physical appearance of the artefacts. Indeed, metal oxalates, and more specifically copper oxalates, were already identified on outdoor-exposed bronzes, though not associated with the phenomenon of cyclic corrosion [29]. Instead, compact patinas of an attractive green colour are created on the bronze surface. Moreover, copper oxalates provide a good protection of the surface, given their high degree of insolubility and chemical stability even in an acidic atmosphere [30]. On this basis, an alternative green strategy for the preservation of copper-based artefacts has been proposed. A specific strain of Beauveria bassiana isolated from vineyard soils highly contaminated with copper was tested. It has shown the best performance with an almost 100\% rate of conversion of copper hydroxysulfates and hydroxychlorides into copper oxalates [31,32]. The newly formed copper oxalates were characterized in-depth to define their properties and to optimize the application procedure on corroded coupons [33-35]. Cross-section examination suggested that the first micrometers of an urban natural patina were completely converted into copper oxalates. The same results were obtained for foundry patinas based on copper nitrates, copper chlorides, copper sulfates and iron nitrates as well [36-38].

We also compared the same bio-based treatment to BTA in terms of conversion of corrosion products and corrosion stabilization of a patina composed of copper chlorides. A weathered copper roof tile was used as the base material to prepare coupons with an artificial atacamite patina. This naturally-corroded samples were selected as they are expected to be more representative of real artefacts than bare copper samples. In fact, the properties of corroded surfaces (roughness, morphology and composition) play a key role in the behaviour of conservation treatments. These characteristics must be taken into account when dealing with application on heritage metal surfaces. Indeed, the corrosion layers are part of the historical value of the objects and must not be removed. However, no generally accepted procedure is yet established to cope with the needs of representative corroded cultural heritage surfaces as available standardised methods only refer to clean metal surfaces [39]. Furthermore, the limited possibilities to test on real artwork require to use non-destructive techniques, as well as the testing of new technologies on corroded coupons as a proxy to real artefacts.

The effect of the bio-based and the BTA treatments on corroded samples were assessed on both the surface and cross-sections of the naturally-corroded samples. A multi-analytical approach using Fourier Transform Infrared Spectroscopy (FTIR), Scanning Electron Microscopy (SEM) and Electrochemical Impedance Spectroscopy (EIS) was adopted. The EIS setup enables to perform measurements on both coupons and real artworks allowing for a more straightforward comparison of results in future applications of either treatment.

\section{Materials and methods}

\subsection{Samples production and preparation}

Nine samples $(2.5 \times 2.5 \mathrm{~cm})$ were cut from a naturally aged copper roof tile from Neuchatel, Switzerland. All copper samples exhibited a typical urban natural patina mainly composed of brochantite, a copper hydroxysulfate $\mathrm{Cu}_{4} \mathrm{SO}_{4}(\mathrm{OH})_{6}$ and cuprite, a cuprous oxide $\mathrm{Cu}_{2} \mathrm{O}$, underneath. The samples' surfaces were washed with acetone in an ultrasound bath with acetone and then dried using compressed air. An artificial patina of copper chlorides was then produced starting from the original patina. A solution with $20 \mathrm{~g} \mathrm{Cu}\left(\mathrm{NO}_{3}\right)_{2} \cdot 3 \mathrm{H}_{2} \mathrm{O}$ (Fluka Germany, purum p.a.) and $20 \mathrm{~g} \mathrm{NaCl}$ (Panreac Spain, PA-ACS-ISO) in $100 \mathrm{~mL}$ deionized water was prepared. The samples were sprayed with this solution and left air dry on a soft cloth. The procedure was repeated twice a day for five consecutive days and finally all samples were rinsed with deionised water [40-42]. Fourier-Transform Infrared
Spectroscopy was used to characterize the newly formed artificial patina: it was mostly composed of atacamite, a copper hydroxychloride $\mathrm{Cu}_{2}(\mathrm{OH})_{3} \mathrm{Cl}$ with some traces of brochantite.

The bio-based treatment (biopatina) is based on a gelified culture of the fungal strain S6 of Beauveria bassiana [31-38]. To this purpose, the fungus was dispersed in a water solution amended with nutrients and mixed with a solidifying agent. Samples were covered with the obtained gel during 14 days. After treatment the gel was removed and samples were rinsed first with deionized water and then with ethanol $(70 \% \mathrm{w} / \mathrm{w}$ solution in deionized water) to remove any fungal residue. The samples were dried using compressed air.

A $3 \% \mathrm{w} / \mathrm{V}$ solution of benzotriazole in ethanol $(95 \% \mathrm{w} / \mathrm{w}$ solution in deionized water) was prepared. Two different application protocols were employed. For the first application protocol (BTA1) the corroded samples were fully immersed and left in the solution for $24 \mathrm{~h}$ according to protocols commonly used by conservator-restorers on archaeological objects. The second application protocol (BTA2) involved longer immersion time. The corroded samples described above were fully immersed and left in the BTA solution for 14 days (same duration as for the bio-based treatment) to allow for a better comparison of the results. At the end of either treatment, samples were rinsed with ethanol and dried using compressed air. Finally, a group of samples was left untreated as reference for comparison purposes.

All treatments were performed in triplicates.

\subsection{Surface characterisation}

Before and after treatment, all samples were documented with a scanner HP1110 using a resolution of 600 dpi and setting the white balance with a white paper (Fig. 1). This procedure allowed to evaluate the impact of treatments on the aesthetic appearance of the surface.

\subsubsection{Fourier transform infrared spectroscopy (FTIR)}

FTIR analyses were performed on the surface of the samples without any preparation using a Nicolet iS5 Thermo Scientific spectrometer with a diamond Attenuated Total Reflectance (ATR) crystal plate (iD5 ${ }^{\mathrm{TM}}$ ATR accessory). All spectra were acquired in the range $4000-550 \mathrm{~cm}^{-1}$, at a spectral resolution of $4 \mathrm{~cm}^{-1}$. A total of 32 scans were recorded and the resulting interferograms averaged. Data collection and post-run processing were carried out using Omnic ${ }^{\mathrm{TM}}$ software.

\subsubsection{Scanning electron microscopy (SEM)}

Secondary electron images were acquired using a Philips ESEM XL30 FEG scanning electron microscope with a working distance of $10 \mathrm{~mm}$ and an acceleration voltage of $20 \mathrm{kV}$.

\subsubsection{Electrochemical impedance spectroscopy (EIS)}

EIS measurements were performed with a specially designed contact probe (ST15) which can be used for in-field measurements on artworks $[43,44]$. A stainless steel pseudo-reference electrode is embedded in PTFE coaxially with a $316 \mathrm{~L}$ Stainless Steel Counter Electrode to form a solid contact cell. The nominal area is $1.77 \mathrm{~cm}^{2}$. The electrolyte used here is a mineral water (electrical conductivity $320 \mu \mathrm{S} . \mathrm{cm}^{-1}, \mathrm{pH}=7.9$ ) also adopted for field EIS measurements on outdoor bronze artworks as reported in other studies in the conservation field [45]. A commercial cleaning-cloth is soaked with the electrolyte for $120 \mathrm{~min}$, then fixed to the contact cell. The system obtained is then placed on the surface to be measured; the open circuit potential is monitored to check for sufficient stabilisation. The EIS spectra acquisition is started after approximately $30 \mathrm{~min}$ when the potential variation over the measurement time is not greater than the applied voltage perturbation. Spectra with 10 points per decade were acquired in potentiostatic mode with $10 \mathrm{mV}$ AC signal level at open circuit potential, in the frequency range $100 \mathrm{KHz}$ $10 \mathrm{mHz}$, using a Gamry REF600, with Framework/EIS300 V5.3 software (C2007, Gamry Instruments, Inc. In order to properly normalise the acquired data for the measurement area, the wet footprint of the EIS 


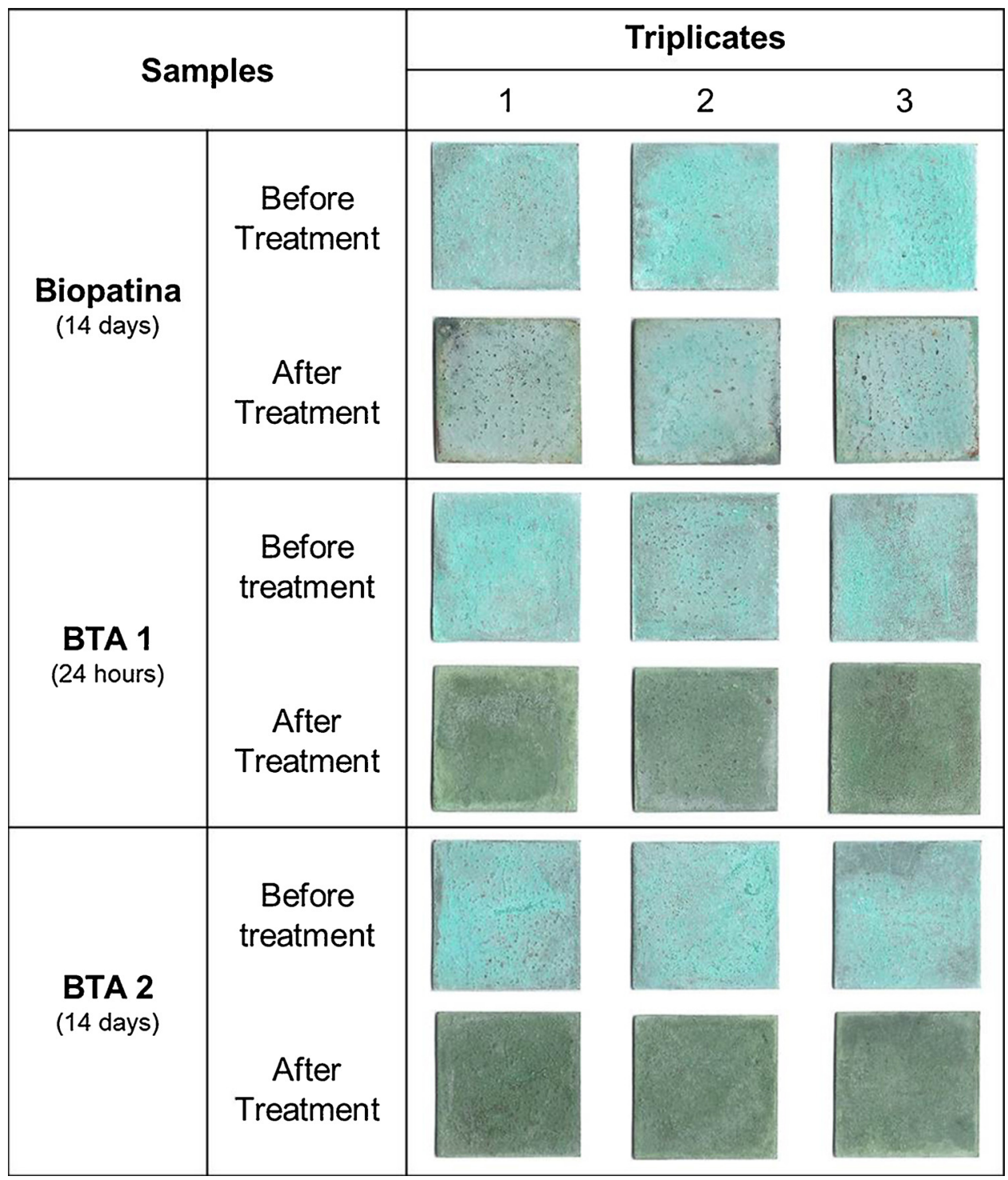

Fig. 1. Samples appearance before and after treatment.

contact probe was recorded with a VEHO VMS-004 usb Microscope by MicroCapture software with a graph paper as background. At least two measurements for each group of samples were made to evaluate treatment reproducibility and homogeneity within the samples.

\subsection{Cross-section characterisation}

One sample for each group (untreated, biopatina, BTA1, BTA2) was cold-embedded in resin using the EpoFix Kit (Struers). Samples were cross-sectioned and dry-polished using successive silicon carbide abrasive papers with 250, 500 and 1000 grit and Micro-Mesh abrasive cloths with 1800, 2400, 3200, 3600, 4000, 6000, 8000 and 12,000 grade.

\subsubsection{Optical microscopy}

Dark-field observation of the cross-sections was performed using a Polyvar MET optical microscope by Reichert Jung with fixed oculars of 10x and Epiplan-Neofluar objectives of 2.5x, 5x, 10x, 20x, and 50x magnification. Photomicrographs were recorded with AxioVision LE software.

\subsubsection{Fourier transform infrared spectroscopy (FTIR)}

FTIR mapping was performed on cross-sections using a Thermo
Scientific Nicolet iN10 MX FTIR microscope in ATR mode (with an ATR Germanium crystal). All spectra were acquired in the range $4000-675 \mathrm{~cm}^{-1}$, at a spectral resolution of $4 \mathrm{~cm}^{-1}$ and a step size of $20 \times 20 \mu \mathrm{m}$. A total of 16 scans per point were recorded and the resulting interferograms averaged. Data collection was carried out using Omnic Picta ${ }^{\mathrm{TM}}$ software while post running processing was carried out using Omnic Atlus ${ }^{\mathrm{TM}}$ software.

\section{Results and discussion}

\subsection{Surface characterisation}

The aesthetical appearance of the samples changed during BTA treatment resulting in surface darkening (Fig. 1). This effect is already known [46] and has to be considered when BTA solutions are envisaged. The bio-based treatment also changed the appearance of the surface but to a lesser extent (Fig. 1).

To ascertain the formation of Cu-BTA complexes and copper oxalates, FTIR analysis was used to characterize the surface of the samples. As showed in Fig. 2, characteristic vibrational bands corresponding to copper oxalates at 1641,1362, 1319 and $816 \mathrm{~cm}^{-1}$ were identified in samples treated with the bio-based treatment. Peaks at 


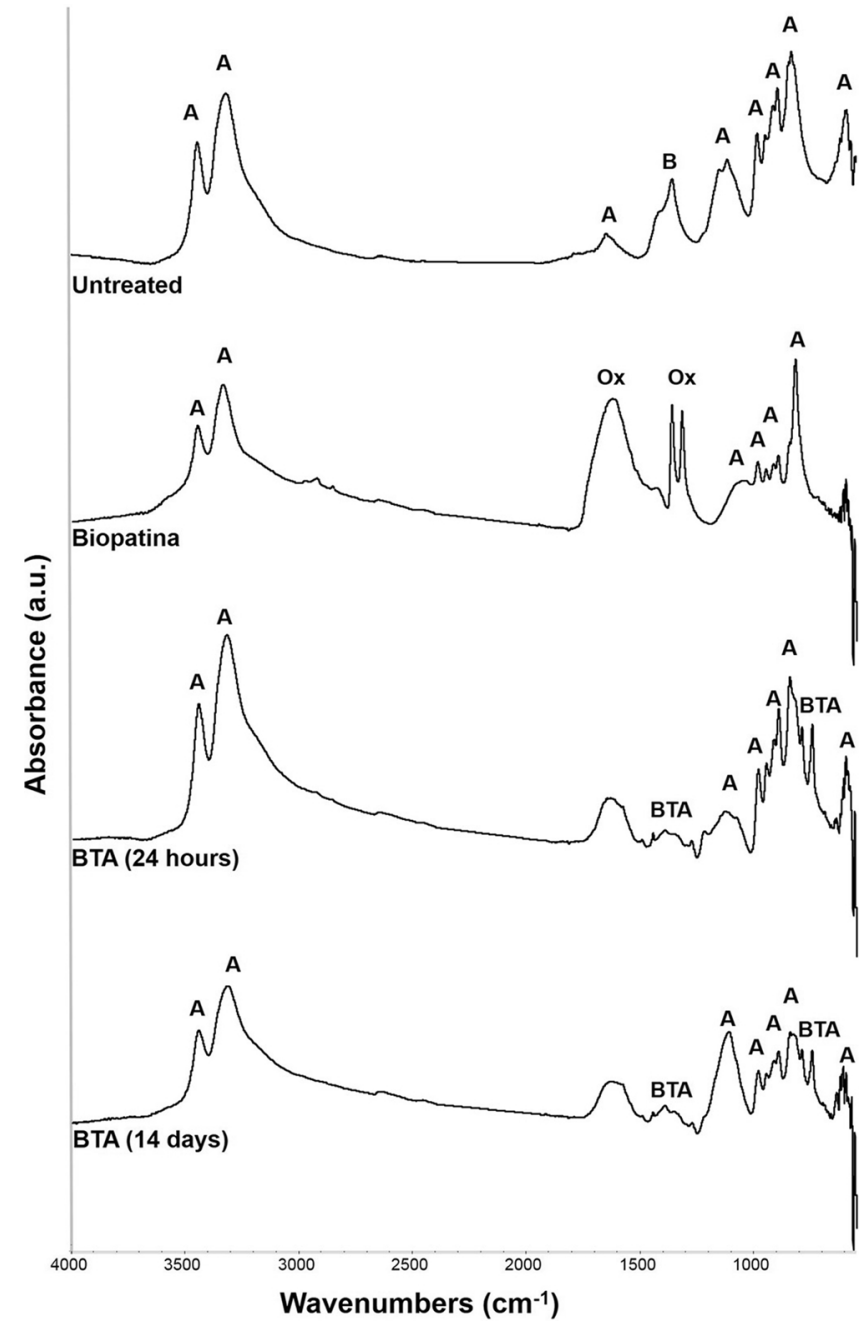

Fig. 2. From top to bottom, ATR-FTIR spectra recorded on untreated sample and treated samples with biopatina, BTA1 (24h) and BTA2 (14 days). Vibrational bands corresponding to atacamite, brochantite, copper oxalates and BTA are indicated with the annotations A, B, Ox and BTA respectively.

$3445,3336,985,948,915,894$ and $847 \mathrm{~cm}^{-1}$ corresponding to atacamite were also present. Nevertheless, these peaks presented a lower relative intensity compared to the intensity measured before treatment, indicating a decrease in the abundance of atacamite on the surface of treated samples. On the contrary, the relative intensity of peaks corresponding to copper oxalates is much higher, indicating an increase in their abundance relative to atacamite. Regarding BTA, Cu-BTA complexes were formed in both $24 \mathrm{~h}$ (BTA1) and 14-day (BTA2) applications (Fig. 2). The characteristic peaks at 1494, 1445, 1395, 1298, 1274, 793 and $746 \mathrm{~cm}^{-1}$ for BTA1 (24 h) and at 1493, 1445, 1395, 1297, 1274,790 and $746 \mathrm{~cm}^{-1}$ for BTA2 (14 days) were observed on the surface of the samples [47]. The difference between the two BTA applications concerned the relative intensity of the peaks of the Cu-BTA complexes. In fact, even if a 24-hour application guaranteed the formation of Cu-BTA complexes, a longer BTA application (here 14 days) resulted in an increase in the relative intensity of peaks corresponding to the Cu-BTA complexes compared to those of the untreated patina (3440, 3326, 1649, 1416, 1359, 1156, 1111, 983, 948, 915, 894, 849, $597 \mathrm{~cm}^{-1}$ ). This result could be due to a higher degree of reaction of the BTA solution with the artificially corroded surface because of the extended exposure leading to the formation of a higher number of Cu-BTA complexes.

SEM observations showed that, compared with the untreated samples (Fig. 3a), the surfaces of biologically treated samples were covered with crystals presenting the typical rosette-like habita of copper oxalates (Fig. 3b). Regarding the BTA-treated samples, both protocols showed the appearance of new structures probably due to the formation of Cu-BTA complexes (Fig. 3b and c). Also, it seems that the first layer of corrosion product covering the control sample (Fig. 3a) was lifted or removed by the BTA treatment, exposing the cubic corrosion underneath (Fig. 3b and c).

The protective behaviour of treatments was evaluated using electrochemical impedance spectroscopy (EIS). The large variability of results on the replicates suggests the uneven behaviour of the samples (Fig. 4). All the Nyquist plots showed the flattened semicircles indicating non-uniform and rough surfaces and the presence of (at least) two typical processes of porous layers. Different equivalent circuit (EC) models could fit the complex behaviour of corroded copper-based surfaces [47-50]. However, a qualitative comparison of the curve shapes and low frequency values of impedance modulus have proved to allow an effective comparison between different surface treatments for heritage metal substrates $[44,51,52]$. Bode plots for untreated samples were characterised by a low frequency $|\mathrm{Z}|$ of the order of $10 \mathrm{k} \Omega \mathrm{cm}^{2}$ (Fig. 5) as already reported for pure copper immersed in artificial urban rain [48]. It is worth highlighting that the variability of the values indicates electrochemical processes related to the presence of inhomogeneous corrosion layers (Fig. 4a). The overall shape of EIS spectra recorded on both BTA-treated samples is similar to those of untreated samples. However, the protocol BTA2 (14 days) showed a better repeatability than protocol BTA1 ( $24 \mathrm{~h}$ ) (Fig. $4 \mathrm{~b}-\mathrm{c}$ ). In both protocols, the $|\mathrm{Z}|$ values were on the same order of magnitude (in the range of $1-10 \mathrm{k} \Omega \mathrm{cm}^{2}$ ) as those of the values for untreated samples, even though systematically lower by a factor of $2-4$, indicating that the BTA treatment is not effective against corrosion on atacamite-rich samples (Fig. 5a and Table 1). This has already been pointed out for pure copper in artificial urban rain [48]. Also, in the BTA1 protocol, the phase plots show larger differences between the measurements, showing a poor reproducibility of the treatment (Fig. 5b). On the contrary, the bio-based treatment clearly increased the patina protectiveness, as indicated by the shape of the EIS spectra with higher phase values at high frequencies (Figs. $4 \mathrm{~d}$ and $5 \mathrm{~b}$ ). In addition, $|\mathrm{Z}|$ values were one order of magnitude higher than those of untreated and BTA-treated samples (Fig. 5a and Table 1).

\subsection{Cross-section characterisation}

To evaluate the efficiency of the treatment within the corrosion layers, the composition and location of the different compounds present was evaluated on cross-sections by means of optical microscopy and FTIR mapping. The untreated samples presented a homogeneous green layer of atacamite (thickness range $22-65 \mu \mathrm{m}$ ). Atacamite was the only compound detected by FTIR and no traces of the original brochantite layer were found on the coupons (Fig. 6). It is worth saying that the signal cut-off at $675 \mathrm{~cm}^{-1}$ of the FTIR microscope avoids the detection of copper oxides, as their main vibrational bands are below this limit (at $480 \mathrm{~cm}^{-1}$ ). Hence, their presence cannot be excluded in the underneath red-coloured layer. On the bio-based treated samples, the conversion of the atacamite layer into copper oxalates was observed (Fig. 7). Indeed, a continuous and intense layer of copper oxalates (thickness range $22-50 \mu \mathrm{m}$ ) was identified as the main compound of the corrosion layers. Nevertheless, a small amount of atacamite was detected in the inner part, even though its presence was uneven (thickness range $0-22 \mu \mathrm{m}$ ) and its FTIR absorbance intensity low. Regarding the treatment with BTA, the amount and homogeneity of Cu-BTA complexes formed on the corroded surface seemed to depend on the treatment duration (Figs. 8 and 9). In fact, a duration of $24 \mathrm{~h}$ was insufficient to allow for the formation of a homogeneous layer of Cu-BTA complexes (Fig. 8). Only a few areas of the corrosion layers showed the presence of Cu-BTA complexes (thickness range 0-24 $\mu \mathrm{m}$ ) and the main component remained atacamite (thickness range $27-50 \mu \mathrm{m}$ ), thus confirming EIS results about the lack of evenness of this treatment. However, even a 

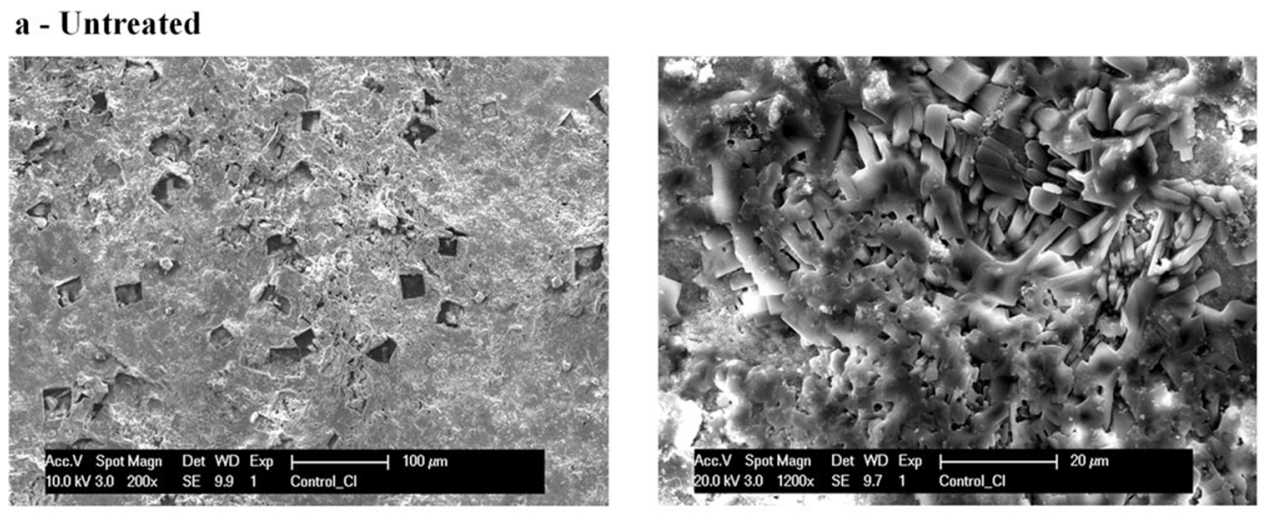

\section{b - Biopatina}
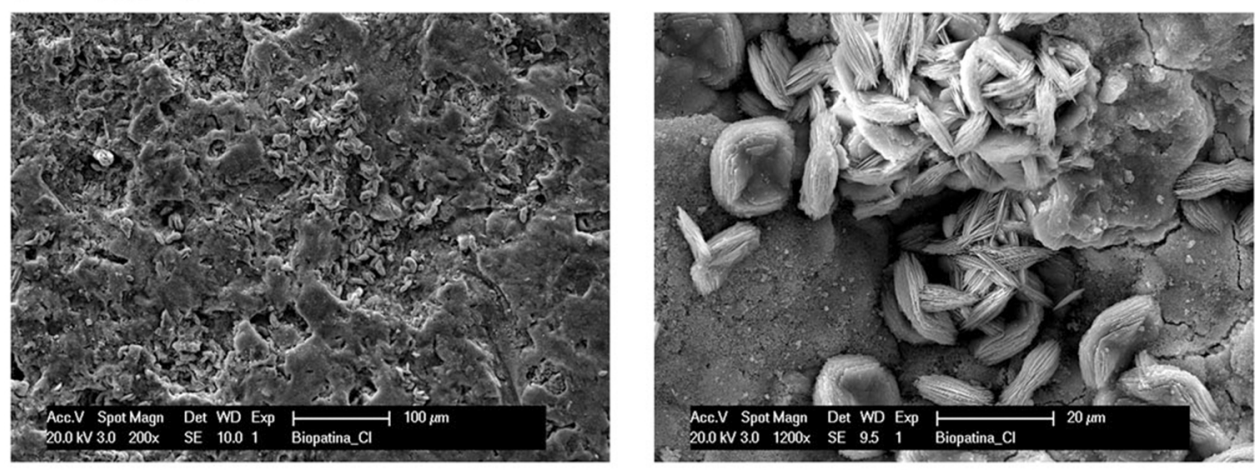

\section{c - BTA $1(24 h)$}
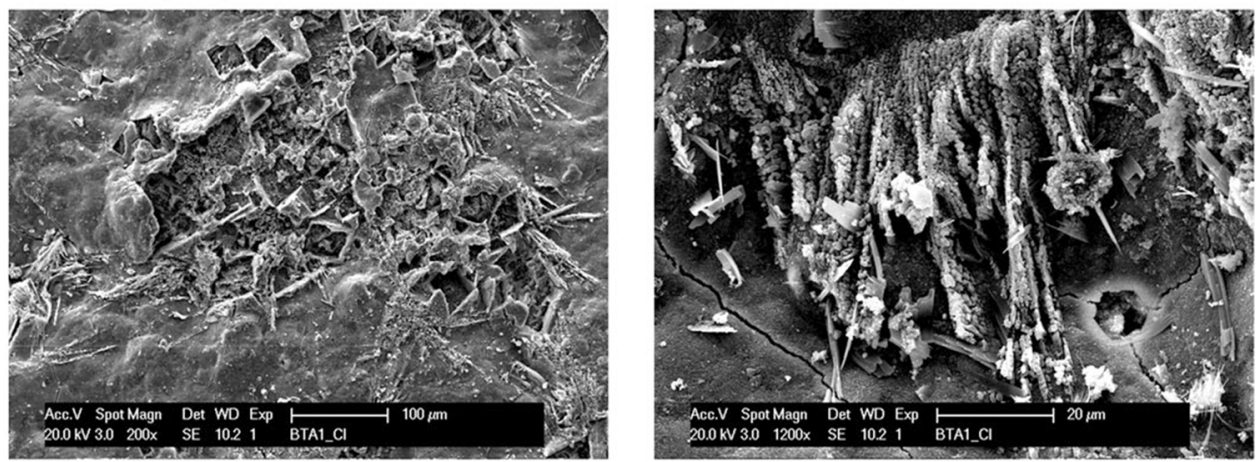

\section{d - BTA 2 (14 days)}
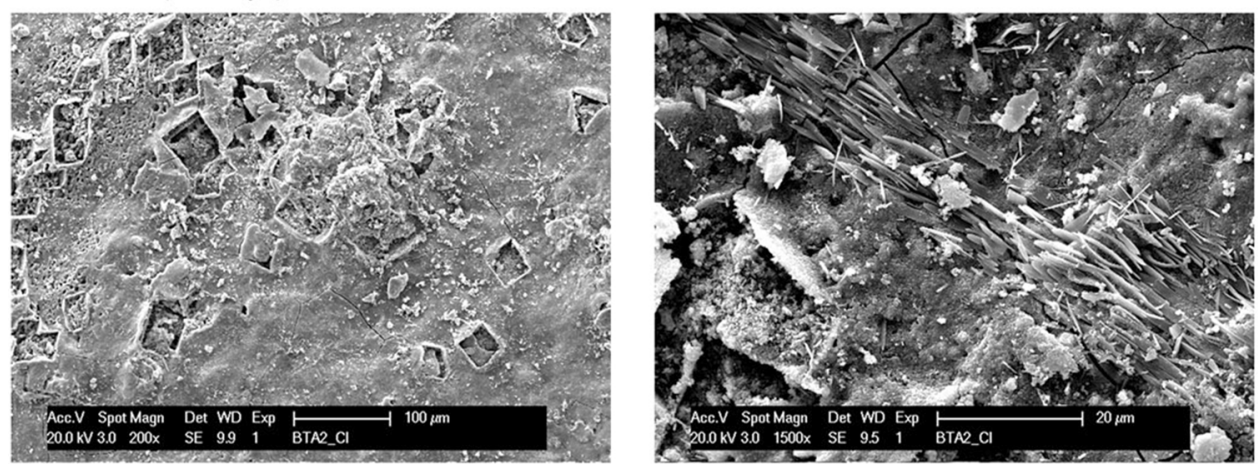

Fig. 3. Secondary electron micrographs obtained from (a) untreated, (b) biologically treated, (c) BTA1- and (d) BTA2- treated samples showing the microscopic changes occurring on the surface. 

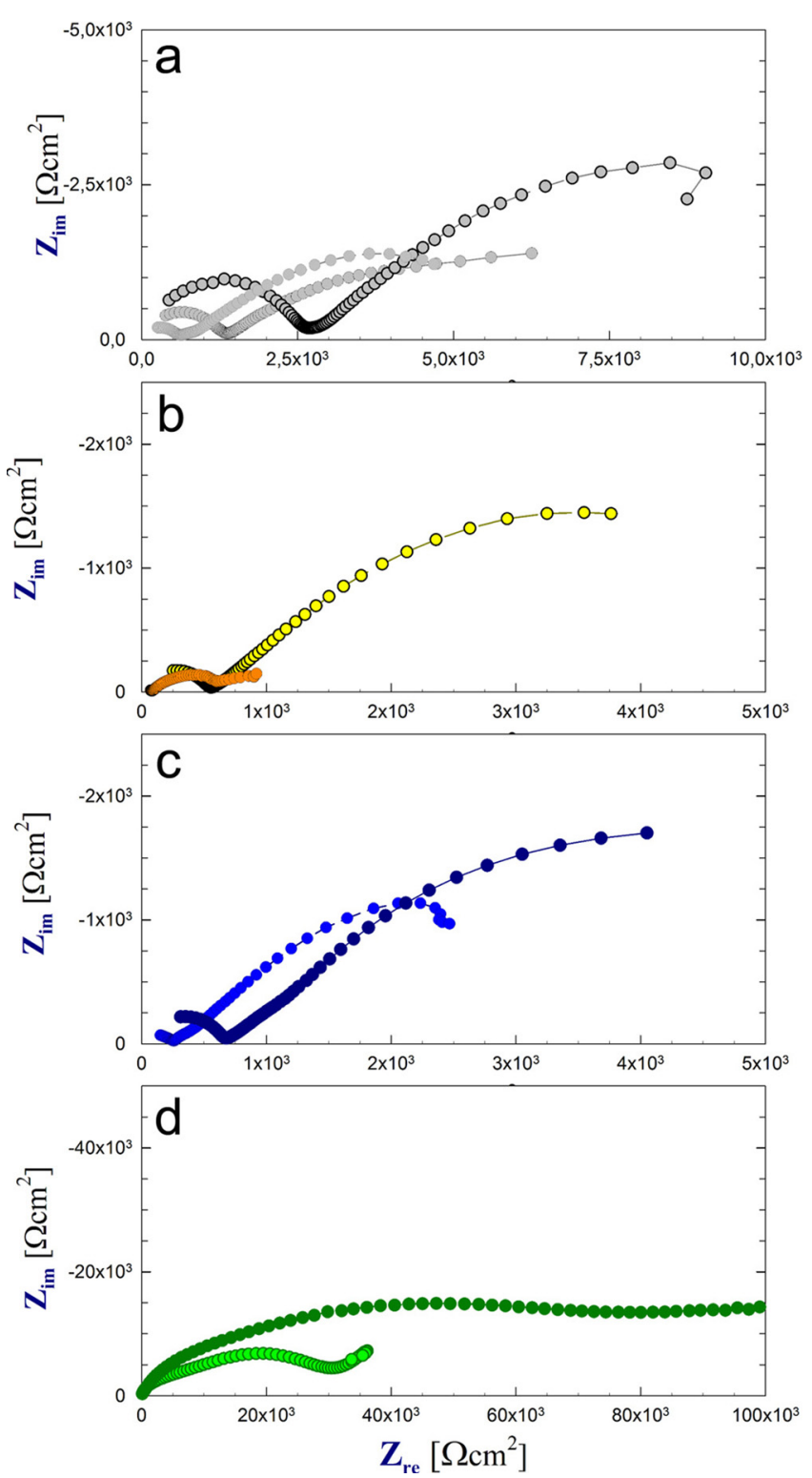

Fig. 4. Nyquist plots of EIS on aged copper coupon with hydroxychloride patina (see text for details) in mineral water (electrical conductivity $320 \mu \mathrm{S} . \mathrm{cm}^{-1}$, $\mathrm{pH}=7.9$ ) with a Contact Probe setup [43]: (a) untreated samples (T0); (b) BTA1 (24 h) treated samples; (d) BTA2 (14days) treated samples; (d) biopatina (T4) treated samples. For each treatment, spectra measured on replicated samples are reported.

longer treatment duration did not guarantee the complete reaction of the atacamite with BTA. Indeed, a continuous layer of atacamite (thickness range 24-32 $\mu \mathrm{m}$ ) was still detected after 14-days treatment with BTA (Fig. 9). The Cu-BTA complexes layer was, in this case, more homogeneous (thickness range $0-32 \mu \mathrm{m}$ ) but the intensity was low, probably because of the simultaneous presence of atacamite in the same area.

As a general observation, it seems that in the bio-based treatment the conversion of the atacamite into copper oxalates started from the surface layers towards the inner core of the corrosion layers. This is probably due to the delivery system used, which gradually released the oxalic acid produced by the fungus and allowing for a progressive diffusion and homogeneous reaction with copper ions. On the contrary, for the BTA treatment, the solution diffused along the pores of the atacamite patina in the entire corrosion layers and reacted simultaneously in different areas at different depth. In addition, the degree of reaction

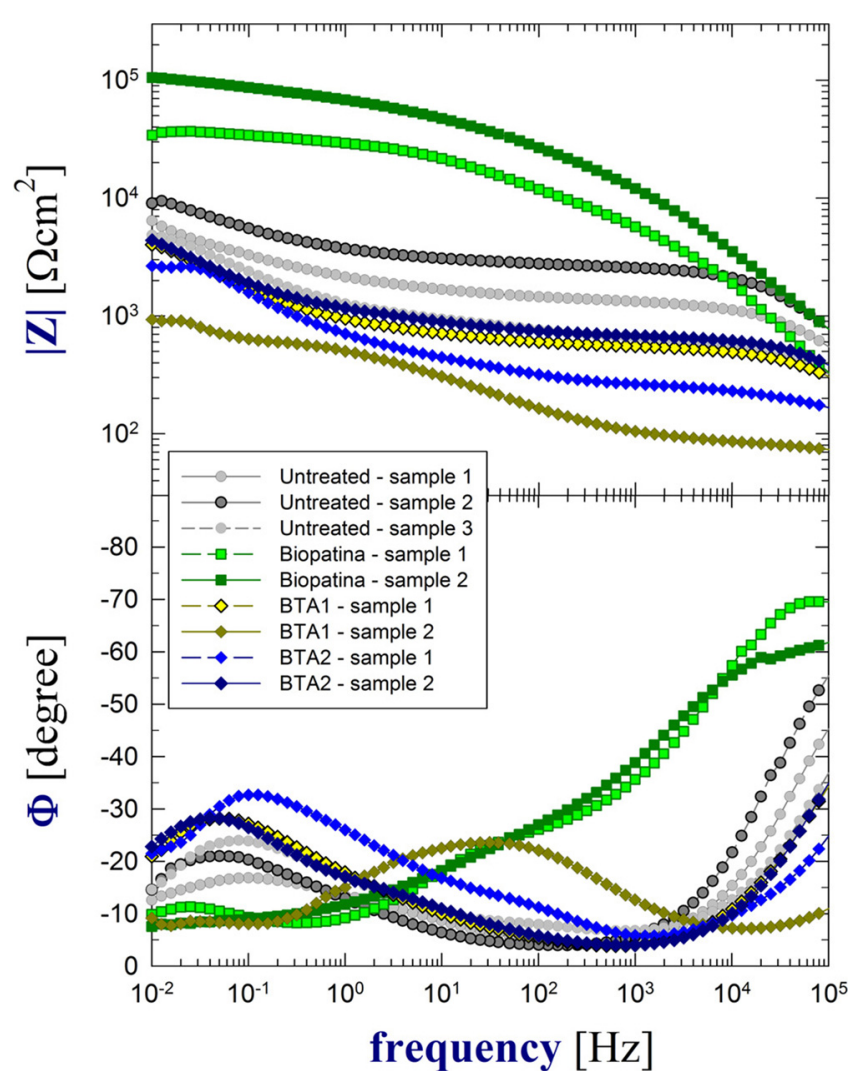

Fig. 5. Bode plot of EIS measurements in Fig. 4: impedance modulus (top) and phase plots (bottom) for untreated (T0, grey circles), biopatina (T4, green squares) and BTA (24 h: BTA1, yellow diamonds; 14 days: BTA2, blue diamonds) treated samples (For interpretation of the references to colour in this figure legend, the reader is referred to the web version of this article.).

Table 1

Low frequency impedance $|\mathrm{Z}|$ values.

\begin{tabular}{llll}
\hline Samples & $|\mathrm{Z}| 10 \mathrm{mHz}\left[\mathrm{k} \Omega \mathrm{cm}^{2}\right]$ & & \\
\hline Control & 7 & \pm & 2 \\
BTA1 (24 hours) & 2 & \pm & 2 \\
BTA2 (14 days) & 4 & \pm & 1 \\
Biopatina & 70 & \pm & 50
\end{tabular}

Average impedance modulus $|\mathrm{Z}|$ limit values at low frequency normalised for the measurement area of the untreated samples (Control) and of all treatments (BTA 1, BTA2 and Biopatina). The values indicate an increase of the $|\mathrm{Z}|$ limit values for the biopatina treated samples while for both BTA treatments the values remain in the untreated samples range.

appeared to be dependent of the immersion time ( $24 \mathrm{~h}$ versus 14 days). Another observation concerns the thickness of the final patina. The patina is thicker on untreated samples than on treated ones, regardless of the method used. The bio-based treatment decreased the patina thickness by a maximum of $15 \mu \mathrm{m}$, while BTA treatment decreased the patina thickness, according to the treatment duration (from $15 \mu \mathrm{m}$ for $24 \mathrm{~h}$ to $33 \mu \mathrm{m}$ for 14-day application). In the case of BTA2, this decrease in the thickness corresponds to more than half of the untreated patina $(22-65 \mu \mathrm{m})$. However, this phenomenon may be related to the partial dissolution of the patina during immersion in the BTA solution, confirming SEM observations. In fact, artificially-produced patinas are usually less adherent to the metal substrate than natural ones and, thus, a physical detachment might occur, in particular after an extended immersion time (i.e. 14 days). It is important to indicate that for cultural heritage artefacts, the patina loss may, in some cases, preclude the readability of the artefacts itself. Indeed, inscriptions or decorations 

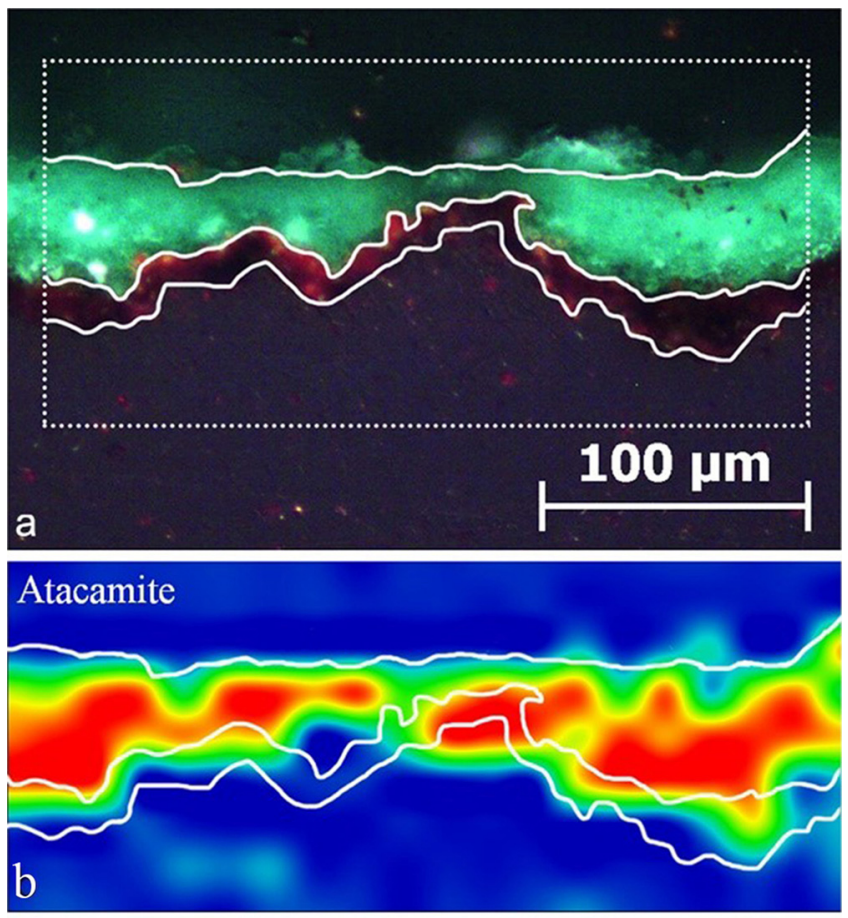

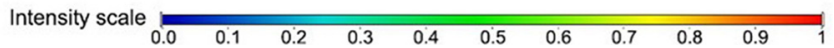

Fig. 6. (a) optical micrograph of untreated sample showing the area (white dotted line) where FTIR mapping was performed and (b) FTIR false colours correlation map with an atacamite reference spectrum.

may remain as "ghost" structures in the corrosion layers and should be preserved. Thus, a removal, even partial, of the patina should be carefully controlled and treatments limiting such loss of material should be preferred.

\section{General discussion}

An additional reflection about the extended use of BTA and its effectiveness must be added. Despite it is usage for more than 50 years, no tested protocol was ever produced for BTA application [53]. Indeed, BTA can be applied either by brush, by immersion of objects under vacuum conditions for a few hours, or by soaking for several days [53]. The most common recipes found in the literature are solutions of $3 \%$ of BTA in ethanol or $1 \%$ of BTA in water $[46,47,53]$. Factors such as the state of the object (in particular the oxidation state of its reactive surface), redox potential, temperature, $\mathrm{pH}$, content of chlorine and oxygen, can all affect the reaction between BTA and copper [47]. In fact, the nature of the complexes formed when BTA is chemically absorbed on the metal depends on the copper oxidation state (i.e. $\mathrm{Cu}(\mathrm{I})$ or $\mathrm{Cu}(\mathrm{II})$ ) [47]. This extended number of variables can explain the inconsistent evidence concerning BTA efficiency, previously mentioned. Research towards more standardised products is thus necessary in order to obtain homogeneous and reproducible results. Furthermore, the controversy about BTA toxicity lead, in the past years, to the development of less toxic corrosion inhibitors. Products made of plant extracts [54] and of amino acids [55-59] were already studied in order to assess their effectiveness against copper and bronze corrosion, even though so far no experiments on real artefacts were conducted, especially in relation with bronze disease. In this context, the bio-based treatment is in an advanced stage compared to the research on real archaeological artefacts and outdoor monuments [30-36]. Furthermore, it uses a microorganism that is reported to be non-toxic for the environment and for human health [60], therefore overcoming the issue of toxicity.
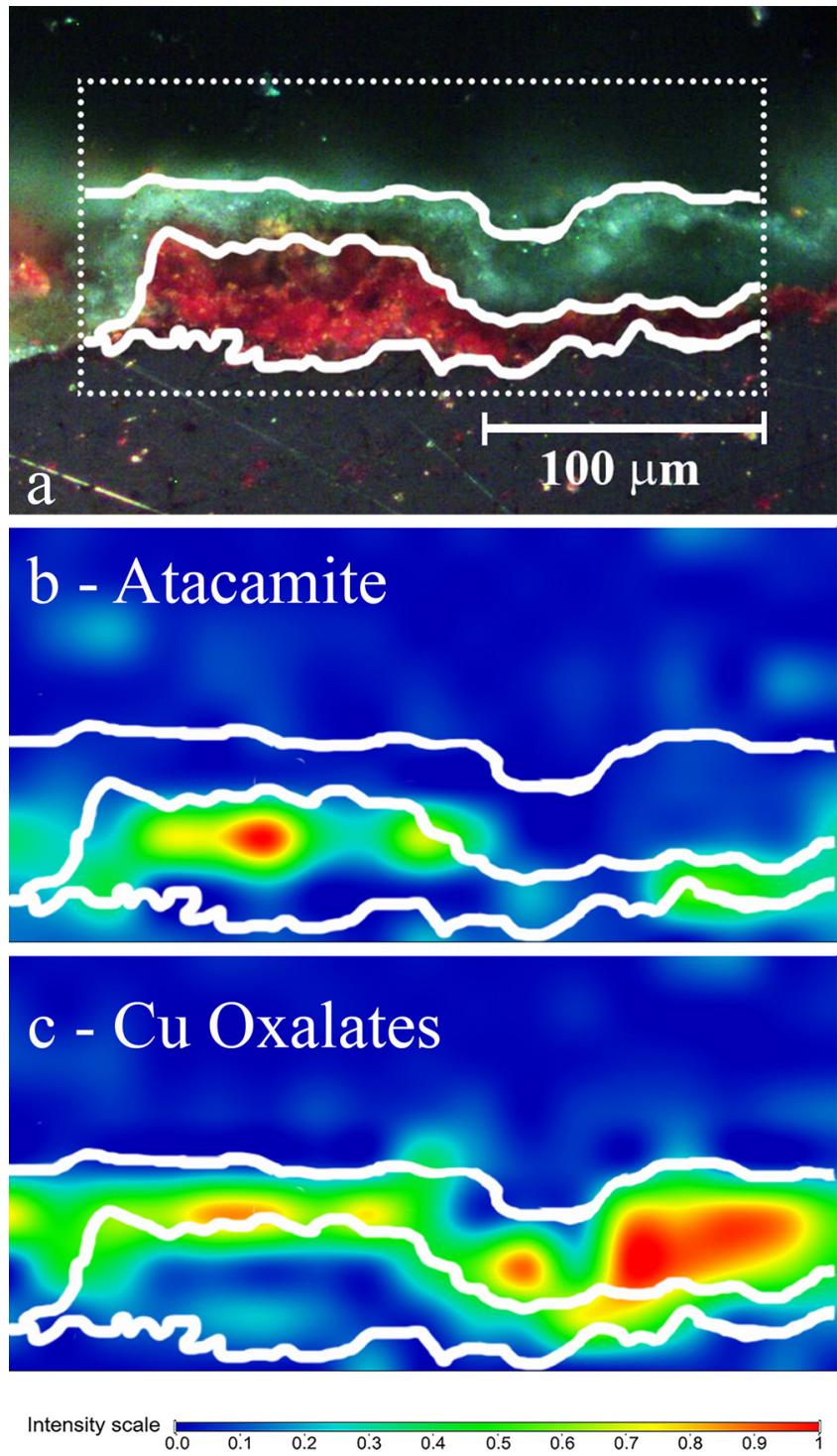

Fig. 7. (a) optical micrograph of biopatina treated sample showing the area (white dotted line) where FTIR mapping was performed. FTIR false colours correlation maps with a reference spectrum of (b) atacamite and of (c) copper oxalates.

\section{Conclusions}

This paper aimed to compare the efficiency of a reference corrosion inhibitor (BTA) and an innovative bio-based treatment in terms of conversion and stabilization of $\mathrm{CH}$ corroded surfaces. BTA was applied for $24 \mathrm{~h}$ (BTA1) and 14 days (BTA2). The 24-hour application was insufficient to allow for the formation of a homogeneous layer of Cu-BTA complexes, therefore resulting in poor surface protectiveness. To obtain a more homogeneous layer of Cu-BTA complexes, 14 days were needed. Nonetheless, in both cases, the efficiency of BTA in terms of corrosion inhibition was not sufficient. In fact, the protective behaviour deduced from EIS measurements suggest the same behaviour, if not worst, as observed for untreated samples. On the contrary, the bio-based treatment used in this study converted almost all of the atacamite present, into a homogeneous layer of copper oxalates. The presence of copper oxalates also enhanced the surface inhibition against corrosion compared both with untreated and BTA-treated patinas. In addition, the bio-based treatment, being non-toxic for the environment and for human health, overcomes the toxicity issue of BTA. To conclude, biobased treatment appears to be an efficient and safe corrosion inhibition 

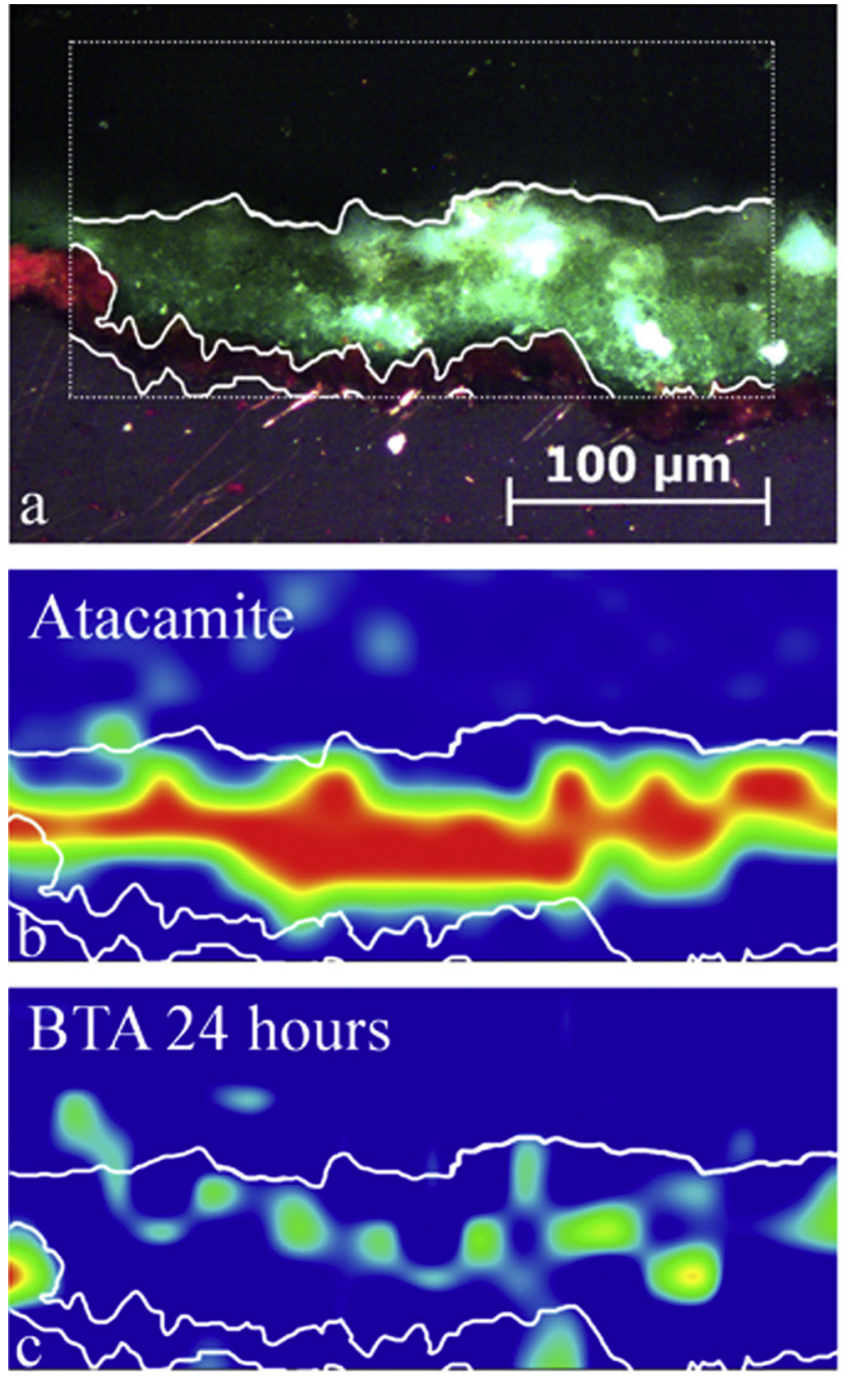

Intensity scale

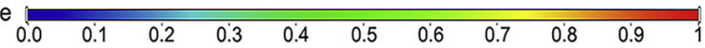

Fig. 8. (a) Optical micrograph of 24-hours treated BTA sample showing the area (white dotted line) where FTIR mapping was performed. FTIR false colours maps representing (b) atacamite (correlation map with a reference spectrum) and (c) Cu-BTA complexes (peak area $1397 \mathrm{~cm}^{-1}$ ).

treatment. It could represent an effective and eco-friendly alternative to the use of BTA for the inhibition of an active corrosion process such as bronze disease.

\section{Data availability}

The raw and processed data required to reproduce these findings cannot be shared at this time due to legal or ethical reasons.

\section{Acknowledgments}

This research was financially supported by the Stiftung zur Förderung der Denkmalpflege (New ecological and sustainable solution for protecting architectural metals using an ecologically friendly biological treatment, 2015-2018) and the Réseau de Compétences Design et Arts visuels, University of Applied Sciences Western Switzerland HES-SO (PluMBER-Patina for Metal Built Heritage, no. 44499, 2015-2018).
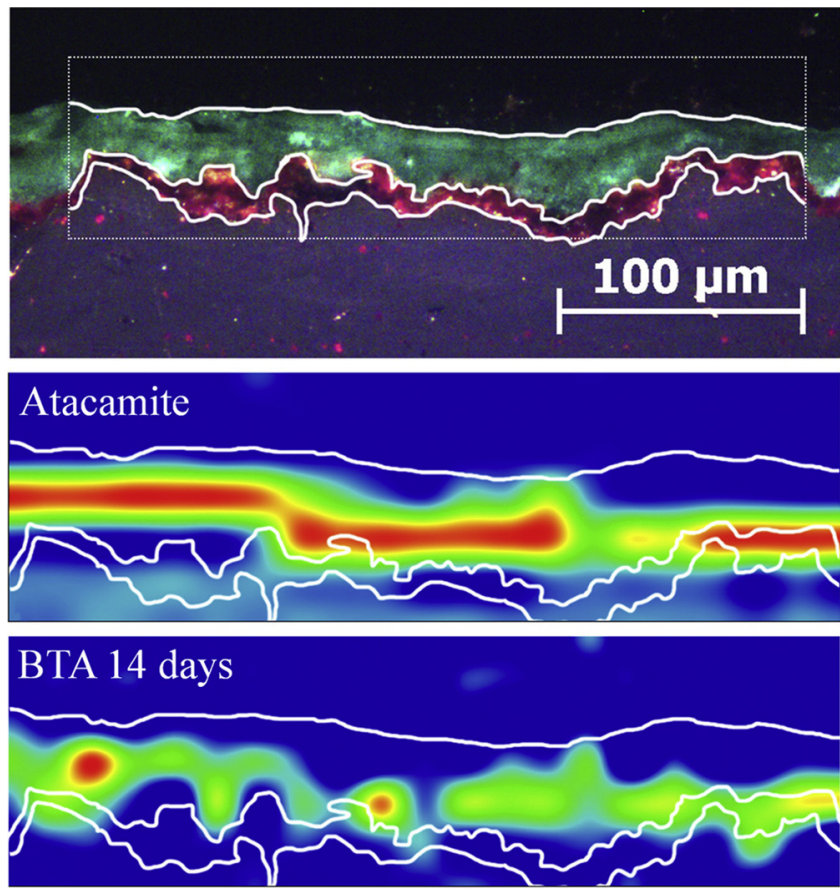

Intensity scale $\begin{array}{llllllllll}0.0 & 0.1 & 0.2 & 0.3 & 0.4 & 0.5 & 0.6 & 0.7 & 0.8 & 0.9\end{array}$

Fig. 9. From top to bottom, optical micrograph of 14-days treated BTA sample and respective FTIR false colours maps representing atacamite (correlation map with a reference spectrum) and Cu-BTA complexes (peak area $1397 \mathrm{~cm}^{-1}$ ).

\section{References}

[1] B. Appelbaum, Conservation Treatment Methodology, Elsevier, Oxford, 2007.

[2] D.A. Scott, Copper and Bronze in Art: Corrosion, Colorants, Conservation, Getty Pubblications, 2002.

[3] D.A. Scott, Bronze disease: a review of some chemical problems and the role of relative humidity, J. Am. Inst. Conserv. 29 (2) (1990) 193-206.

[4] R. Grayburn, M. Dowsett, M. Hand, P.J. Sabbe, P. Thompson, M. Adriaens, Tracking the progression of bronze disease-a synchrotron $\mathrm{x}$-ray diffraction study of nantokite hydrolysis, Corros. Sci. 91 (2015) 220-223.

[5] I.D. MacLeod, Bronze disease: an electrochemical explanation, ICCM Bull. 7 (1) (1981) 16-26.

[6] T. Malcherek, J. Schlüter, Structures of the pseudo-trigonal polymorphs of $\mathrm{Cu}_{2}(\mathrm{OH})_{3} \mathrm{Cl}$, J. Acta Crystallogr., Sect. B: Struct. Sci., Cryst. Eng. Mater. 65 (3) (2009) 334-341.

[7] M. Finšgar, I. Milošev, Inhibition of copper corrosion by 1, 2, 3-benzotriazole: a review, Corros. Sci. 52 (9) (2010) 2737-2749.

[8] S. Golfomitsou, J. Merkel, Synergistic effects of corrosion inhibitors for copper and copper alloy archaeological artefacts, in: J. Ashton, D. Hallam (Eds.), Metal 2004. Proceedings of the Interim Meeting of ICOM-CC Metal WG (2004) 344-368.

[9] I.D. MacLeod, Conservation of corroded copper alloys: a comparison of new and traditional methods for removing chloride ions, Stud. Conserv. 32 (1) (1987) 25-40.

[10] R. Faltermeier, Testing corrosion inhibitors for the conservation of archaeological copper and copper alloys, J. Conserv. Mus. Stud. 3 (1997).

[11] V. Argyropoulos, A. Hein, M.A. Harith, A survey of the types of corrosion inhibitors and protective coatings used for the conservation of metal objects from museum collections in the Mediterranean basin, in strategies for saving our cultural heritage, Proceedings of the International Conference on Conservation Strategies for Saving Indoor Metallic Collections. Cairo (Egypt) (2007).

[12] H. Hassairi, L. Bousselmi, S. Khosrof, E. Triki, Characterization of archaeologica bronze and evaluation of the benzotriazole efficiency in alkali medium, Mater. Corros. 59 (1) (2008) 32-40.

[13] A. Balbo, C. Chiavari, C. Martini, C. Monticelli, Effectiveness of corrosion inhibitor films for the conservation of bronzes and gilded bronzes, Corros. Sci. 59 (2012) 204-212.

[14] A. Mezzi, E. Angelini, T. De Caro, S. Grassini, F. Faraldi, C. Riccucci, G.M. Ingo, Investigation of the benzotriazole inhibition mechanism of bronze disease, Surf. Interface Anal. 44 (8) (2012) 968-971.

[15] A.N. Abu-Baker, D. MacLeod, R. Sloggett, R. Taylor, A comparative study of salicylaldoxime, cysteine and benzotriazole as inhibitors for the activechloride-based corrosion of copper and bronze artifacts, Eur. Sci. J. 9 (33) (2013).

[16] H. Hassairi, L. Bousselmi, S. Khosrof, E. Triki, Evaluation of the inhibitive effect of benzotriazole on archeological bronze in acidic medium, Appl. Phys. A 113 (4) (2013) 923-931. 
[17] E. Cano, D. Lafuente, et al., Corrosion inhibitors for the preservation of metallic heritage artefacts, in: P. Dillmann (Ed.), Corrosion and Conservation of Cultural Heritage Artefacts, Woodhead Publishing, 2013, pp. 570-594.

[18] C. Sease, Benzotriazole: a review for conservators, Stud. Conserv. 23 (2) (1978) 76-85.

[19] C.A. Harris, E.J. Routledge, C. Schaffner, J.V. Brian, W. Giger, J.P. Sumpter, Benzotriazole is antiestrogenic in vitro but not in vivo, Environ. Toxicol. Chem. 26 (11) (2007) 2367-2372.

[20] Green Conservation of Cultural Heritage Conference, (2015) Communications available at http://www.restaurosostenibile.eu/2015/08/14/video/.

[21] E.P. Burford, M. Fomina, G.M. Gadd, Fungal involvement in bioweathering and biotransformation of rocks and minerals, Mineral. Mag. 67 (6) (2003) 1127-1155.

[22] G.M. Gadd, Interactions of fungi with toxic metals, New Phytol. 124 (1) (1993) 25-60.

[23] A. Jarosz-Wilkolazka, G.M. Gadd, Oxalate production by wood-rotting fungi growing in toxic metal-amended medium, Chemosphere 52 (3) (2003) 541-547.

[24] G.M. Gadd, Geomycology: biogeochemical transformations of rocks, minerals, metals and radionuclides by fungi, bioweathering and bioremediation, Mycol. Res. 111 (1) (2007) 3-49.

[25] G.M. Gadd, Metals, minerals and microbes: geomicrobiology and bioremediation, Microbiology 156 (3) (2010) 609-643.

[26] H.H. Tabak, P.N.L. Lens, E.D. Hullebusch, W. van Dejonghe, Developments in bioremediation of soils and sediments polluted with metals and radionuclides-1. Microbial processes and mechanisms affecting bioremediation of metal contamination and influencing metal toxicity and transport, Rev. Environ. Sci. Biotechnol. 4 (3) (2005) 115-156.

[27] B. Godlewska-Żyłkiewicz, Microorganisms in inorganic chemical analysis, Anal. Bioanal. Chem. 384 (1) (2006) 114-123.

[28] G.S. Sayler, R. Fox, J. Blackburn, Environmental Biotechnology for Waste Treatment Vol. 41 Springer Science \& Business Media, 2013.

[29] T.E. Graedel, K. Nassau, J.P. Franey, Copper Patina Formation: copper patinas formed in the atmosphere - I, Corros. Sci. 27 (7) (1987) 639-657.

[30] M. Marabelli, R. Mazzeo, La corrosione dei bronzi esposti all'aperto: problemi di caratterizzazione, Metallurgia Italiana 85 (1993) 247.

[31] R. Mazzeo, S. Bittner, D. Job, G. Farron, R. Fontinha, E. Joseph, P. Letardi, M. Mach, S. Prati, M. Salta, A. Simon, Development and evaluation of New treatments for outdoor bronze monuments, in: J. Townsend, L. Toniolo, F. Cappitelli (Eds.), Conservation Science, Archetype publications Ltd, London, 2007, pp. 40-48.

[32] E. Joseph, P. Letardi, R. Mazzeo, S. Prati, M. Vandini, Innovative treatments for the protection of outdoor bronze monuments, Metal 2007. Proceeding of the Interim Meeting of ICOM-CC Metal WG (2007) 71-77.

[33] E. Joseph, A. Simon, S. Prati, M. Wörle, D. Job, R. Mazzeo, Development of an analytical procedure for evaluation of the protective behaviour of innovative fungal patinas on archaeological and artistic metal artefacts, Anal. Bioanal. Chem. 399 (2011) 2899-2907.

[34] E. Joseph, S. Cario, A. Simon, M. Wörle, Protection of metal artefacts with the formation of metal-oxalates complexes by Beauveria bassiana, Front. Microbiol. 2 (2012) 270.

[35] E. Joseph, A. Simon, R. Mazzeo, D. Job, M. Wörle, Spectroscopic characterization of an innovative biological treatment for corroded metal artefacts, J. Raman Spectrosc. 43 (11) (2012) 1612-1616.

[36] E. Joseph, P. Letardi, L. Comensoli, A. Simon, P. Junier, D. Job, M. Wörle, Assessment of a biological approach for the protection of copper alloys artefacts, in: E. Hyslop, V. Gonzalez, L. Troalen, L. Wilson (Eds.), Metal 2013, 2013, pp. 203-207 Proceedings of the Interim Meeting of ICOM-CC Metal WG, Edinburgh, Scotland.

[37] E. Joseph, M. Albini, P. Letardi, E. Domon Beuret, L. Brambilla, L. Mathys, C. Cevey, R. Bertholon, D. Job, P. Junier, BIOPATINAS: innovative biological patinas for copper-based artefacts, Outdoor Metallic Sculpture from the XIXth to the Beginning of the XXth Century: Identification, Conservation, Restoration (2014) 154-162.

[38] M. Albini, L. Comensoli, L. Brambilla, E. Domon Beuret, W. Kooli, L. Mathys, P. Letardi, E. Joseph, Innovative biological approaches for metal conservation, Mater. Corros. 67 (2) (2016) 200-206.
[39] V. Argyropoulos, S. Boyatzis, M. Giannoulaki, K. Polikreti, The role of standards in conservation methods for metals in cultural heritage, in: P. Dillmann, D. Watkinson, E. Angelini, A. Adriaens (Eds.), Corrosion and Conservation of Cultural Heritage Artefacts, Woodhead Publishing, 2013, pp. 478-517.

[40] V. Hayez, V. Costa, J. Guillaume, H. Terryn, A. Hubin, Micro Raman spectroscopy used for the study of corrosion products on copper alloys: study of the chemical composition of artificial patinas used for restoration purposes, Analyst 130 (4) (2005) 550-556.

[41] V. Hayez, T. Segato, A. Hubin, H. Terryn, Study of copper nitrate-based patinas, J. Raman Spectrosc. 37 (10) (2006) 1211-1220.

[42] K. Leyssens, A. Adriaens, C. Degrigny, Electrochemical monitoring of the storage or stabilization of archaeological copper based artefacts in sodium sesquicarbonate solutions, ICOM-CC 14th Triennial Meeting (2005).

[43] P. Letardi, Electrochemical measurements in the conservation of metallic heritage artefacts: an overview, in: P. Dillmann, D. Watkinson, E. Angelini, A. Adriaens (Eds.), Corrosion and Conservation of Cultural Heritage Artefacts, Woodhead Publishing, 2013, pp. 126-148.

[44] P. Letardi, B. Salvadori, M. Galeotti, A. Cagnini, S. Porcinai, A. Santagostino Barbone, A. Sansonetti, An in situ multi-analytical approach in the restoration of bronze artefacts, Microchem. J. 125 (2016) 151-158.

[45] C. Degrigny, G. Guibert, S. Ramseyer, G. Rapp, A. Tarchini, Use of Ecorr vs time plots for the qualitative analysis of metallic elements from scientific and technical objects: the SPAMT Test Project, J. Solid State Chem. 14 (3) (2010) 425-435.

[46] R. Faltermeier, Testing corrosion inhibitors for the conservation of archaeological copper and copper, alloys, SSCR J. 9 (1) (1998) 5.

[47] L.B. Brostoff, Coating Strategies for the Protection of Outdoor Bronze Art and Ornamentation, University of Amsterdam, 2003.

[48] G. Žerjav, I. Milošev, Protection of copper against corrosion in simulated urban rain by the combined action of benzotriazole, 2-mercaptobenzimidazole and stearic acid, Corros. Sci. 98 (2015) 180-191.

[49] F.J.R. de Oliveira, D.C.B. Lago, L.F. Senna, L.R.M. de Miranda, E. D'Elia, Study of patina formation on bronze specimens, Materi. Chem. Phys. 115 (2009) 761-770.

[50] D.E. Arceo-Gómez, J. Reyes-Trujeque, G.E. Zambrano-Rengel, T. Pérez-López, R. Orozco-Cruz, Electrochemical characterization of patinas formed on a historic bell from the Cathedral Museum of Campeche - México, world heritage site, Int. J. Electrochem. Sci. 11 (2016) 9379-9393.

[51] B. Ramírez Barat, A. Crespo, E. García, S. Díaz, E. Cano, An EIS study of the conservation treatment of the bronze sphinxes at the Museo Arqueológico Nacional (Madrid), J. Cult. Herit. 24 (2017) 93-99.

[52] T. Kosec, A. Legat, I. Miloev, The comparison of organic protective layers on bronze and copper, Prog. Org. Coat. 69 (2010) 199-206.

[53] D. Watkinson, Preservation of metallic cultural heritage, in: J.A.R. Tony (Ed.), Shreir's Corrosion, Elsevier, Oxford, 2010, pp. 3307-3340.

[54] M.N. El-Haddad, Chitosan as a green inhibitor for copper corrosion in acidic medium, Int. J. Biol. Macromol. 55 (2013) 142-149.

[55] T. Wang, J. Wang, Y. Wu, The inhibition effect and mechanism of l-cysteine on the corrosion of bronze covered with a $\mathrm{CuCl}$ patina, Corros. Sci. 97 (2015) 89-99.

[56] W.A. Badawy, K.M. Ismail, A.M. Fathi, Corrosion control of $\mathrm{Cu}-\mathrm{Ni}$ alloys in neutral chloride solutions by amino acids, Electrochim. Acta 51 (20) (2006) 4182-4189.

[57] K.M. Ismail, Evaluation of cysteine as environmentally friendly corrosion inhibitor for copper in neutral and acidic chloride solutions, Electrochim. Acta 52 (28) (2007) 7811-7819.

[58] K. Khaled, Corrosion control of copper in nitric acid solutions using some amino acids-A combined experimental and theoretical study, Corros. Sci. 52 (10) (2010) 3225-3234.

[59] D.-Q. Zhang, H. Wu, L.X. Gao, Synergistic inhibition effect of l-phenylalanine and rare earth Ce (IV) ion on the corrosion of copper in hydrochloric acid solution, Mater. Chem. Phys. 133 (2) (2012) 981-986.

[60] G. Zimmermann, Review on safety of the entomopathogenic fungi Beauveria bassiana and Beauveria brongniartii, Biocontrol Sci. Technol. 17 (6) (2007) 553-596. 